\title{
Mangrove Spatial Distribution in the Indian Sundarbans: Predicting Salinity-Induced Migration in a Changing Climate
}

\author{
Anirban Mukhopadhyay ${ }^{1}$, David Wheeler ${ }^{2}$, Susmita Dasgupta ${ }^{3}$, Ajanta Dey ${ }^{4} \&$ Istiak Sobhan $^{3}$ \\ ${ }^{1}$ School of Oceanographic Studies, Jadavpur University, Kolkata, West Bengal, India \\ ${ }^{2}$ World Resources Institute, Washington, DC, USA \\ ${ }^{3}$ World Bank, Washington, DC, USA \\ ${ }^{4}$ Nature Environment \& Wildlife Society, Kolkata, West Bengal, India \\ Correspondence: Susmita Dasgupta, Development Research Group, World Bank, Washington, DC, USA. E-mail: \\ sdasgupta@worldbank.org
}

Received: November 12, 2018 Accepted: December 6, 2018 Online Published: January 24, 2019

doi:10.5539/jms.v9n1p1 URL: https://doi.org/10.5539/jms.v9n1p1

\begin{abstract}
This study contributes to understanding the physical and economic impacts of progressive, climate-driven aquatic salinization on the spatial distribution of mangrove species in the Indian Sundarbans, which accounts for about two-fifths of the $10,200 \mathrm{~km}^{2}$ tidal-wetland forest delta. To estimate future mangrove distribution, a five-step analysis was undertaken, using high-resolution spatial assessments. A current (2015) basemap and overlays of salinity tolerance for major mangrove species and their assemblages and projected location-specific aquatic salinity for 2050 were used to predict salinity-induced migration. The results show gain-and-loss patterns, with salt-tolerant species predominating at the expense of freshwater species. These changes are likely to reduce the flow of ecosystem services, adversely affecting the livelihood options of poor people in adjacent areas. Effective management will require establishing baseline data for monitoring system changes over time, protocols for maintaining species health, and support for mangrove regeneration and restoration. Resources should also be directed to alternative livelihoods for mangrove-dependent households. The study recommends an integrated policy approach, focused on rising salinity, changes in mangrove dynamics, and the welfare of mangrove-dependent communities.
\end{abstract}

Keywords: aquatic salinization, climate change, high-resolution assessment, mangrove-dependent livelihood, mangrove migration, spatial distribution, Sundarbans

\section{Introduction}

The mangrove ecosystems of the Sundarbans - the world's largest remaining contiguous mangrove forest situated along coastal segments of Bangladesh (60 percent) and India (40 percent) in the Bay of Bengal—are at increasing risk from the impacts of climate-driven sea-level rise. In this $10,200 \mathrm{~km}^{2}$ tidal-wetland forest delta, as in other globally important mangrove forests, sea-level rise may even threaten the survival of mangrove species. In the past, mangroves have shown considerable resilience to sea-level fluctuations (Alongi, 2002, 2008; Gilman et al., 2006; Erwin, 2009); however, their future rate of adaptation and migration may not keep pace (Ellison $\&$ Stoddart, 1991; Semeniuk, 1994; United Nations Environment Programme, 1994; McLeod \& Salm, 2006; Lange et al., 2010). In the case of the Sundarbans, the extent of permanent inundation is uncertain since sedimentation is still occurring in the active Ganges-Brahmaputra Delta. That said, climate-driven sea-level rise will inevitably have significant implications for the many poor people who depend on the mangrove forest for their livelihoods. (Note 1)

\subsection{Challenges to Healthy Mangroves in the Sundarbans}

In the Sundarbans, the two greatest threats to the health of mangroves in a changing climate are progressive aquatic salinization and shortage of nutrients from freshwater flows (Dasgupta, Kamal, Khan, Choudhury, \& Nishat, 2015a; Dasgupta, Hossain, Huq, \& Wheeler, 2015b; Institute of Water Modeling, 2003; Peterson \& Shireen, 2001; Soil Resources Development Institute, 2000, 2010; United Kingdom Department of Environment, Food \& Rural Affairs, 2007). It is expected that alteration of riverine flows from the Himalayas, combined with sea-level rise, will intensify salinity intrusion as climate change continues (Dasgupta et al., 2015a, b; Dasgupta et 
al., 2014). This increase in aquatic salinization, in turn, is projected to alter the region's hydrological regime and forest ecology (Barik et al., 2018; Dasgupta, Sobhan, \& Wheeler, 2017). Freshwater shortage during the dry season (October-May) is already a serious issue, owing to the decline of some of the major distributaries of the Ganges that feed the Sundarbans. These changes have significant implications for adaptively managing the mangrove forests.

\subsection{Study Aim and Focal Area for Analysis}

Planning for appropriate adaptation, including the development of conservation and sustainable development policies that incorporate rising salinity, changes in mangrove dynamics, and the welfare impacts on poor communities, requires a better understanding of the physical and economic effects of salinity diffusion in the region. To date, high-resolution spatial assessments have been scarce. This study contributes to narrowing this knowledge gap by analyzing the impact of aquatic salinization on the spatial distribution of mangrove species.

The focus of the analysis is the Indian Sundarbans in coastal West Bengal, which accounts for about two-fifths $\left(4,200 \mathrm{~km}^{2}\right)$ of the mangrove wetlands. The Sundarbans Biosphere Reserve in West Bengal encompasses a 9,630 $\mathrm{km}^{2}$ area, consisting of a core zone $\left(1,700 \mathrm{~km}^{2}\right)$ and development $\left(5,300 \mathrm{~km}^{2}\right)$, managed $\left(2,400 \mathrm{~km}^{2}\right)$, and restoration $\left(230 \mathrm{~km}^{2}\right)$ zones (Nandy \& Kuswaha, 2011). The Harinbhanga River (known as the Raymangal, Kalindi, \& Ichhamati in northern areas) demarcates the reserve's international border with Bangladesh. The Indian Sundarbans is said to possess the world's richest tropical mangrove formation (Naskar, 1988). (Note 2)

Although ecologically resilient, mangrove species in the Indian Sundarbans are highly sensitive to hydrological changes (Blasco, Saenger, \& Janodet, 1996), particularly the salinity profile of the adjacent water column or soils. Sea-level rise, driven by climate change and subsidence, is perhaps the greatest threat to mangrove health (McLeod \& Salm, 2006). Because of siltation at off-take, most of the region's rivers are now tidal-fed, having lost their connection with source rivers, which perennially supplied freshwater from glacier melt. Today their estuarine character is maintained only by monsoon runoff (Bhadra, Mukhopadhyay, \& Hazra, 2017; Cole \& Vaidyaraman, 1966; Gopal \& Chauhan, 2006). In recent decades, human-induced hydrologic alterations in the upper reaches of the Bhagirathi Hooghly River and the Ganges-Brahmaputra-Meghna system have also affected freshwater flow. (Note 3) In the foreseeable future, the region is likely to experience further changes in its salinity profile due to saltwater intrusion from sea-level rise. (Note 4)

\section{Method}

To obtain a broader understanding of how progressive, climate-driven aquatic salinization can be expected to affect the future distribution of mangrove species in the Indian Sundarbans, a five-step method was used. These steps are detailed in the subsections below.

\subsection{Generate a Mangroves Basemap from Satellite Data}

Step 1 was to generate a high-resolution basemap of the current (2015) spatial distribution of mangrove species in the Indian Sundarbans. The basemap was prepared using Landsat 8 Operational Land Imager (OLI), sentinel, and hyperspectral data from Hyperion (Figure 1), along with field survey data, in the multi-step procedure described below. (Note 5)

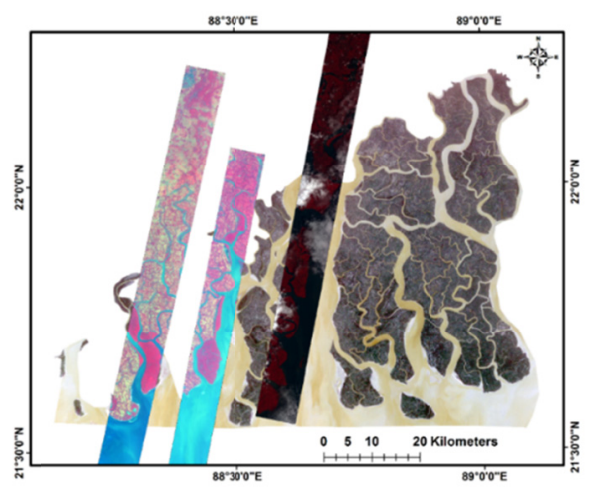

Figure 1. Map showing hyperspectral scenes coverage over mangrove forested areas of the Sundarbans 


\subsubsection{Field Survey}

First, a field survey was conducted at 141 GPS locations to collect geographic location information on five dominant genera of Indian Sundarban mangroves and their assemblages: Avicennia, Ceriops, Excoecaria, Heritiera, and Sonneratia. This information was later used to generate a spectral signature of the mangroves and validate the interpretation of satellite images.

\subsubsection{Spectral Profile Generation for Mangrove Species}

Second, spectral profiles of the mangrove species were generated from hyperspectral imagery from Hyperion. Out of 242 bands of Hyperion images, 67 were eliminated (i.e., water-vapor absorption bands and those for overlapping regions or without data) (Barry, 2001; Datt, McVicar, Van Niel, Jupp, \& Pearlman, 2003). (Note 6) The remaining 175 calibrated bands underwent visual and statistical examination, and signal-to-noise ratios were determined for all. At this stage, de-striping and atmospheric corrections were made, which provided calibrated image spectra of the species (Figure 2). (Note 7).
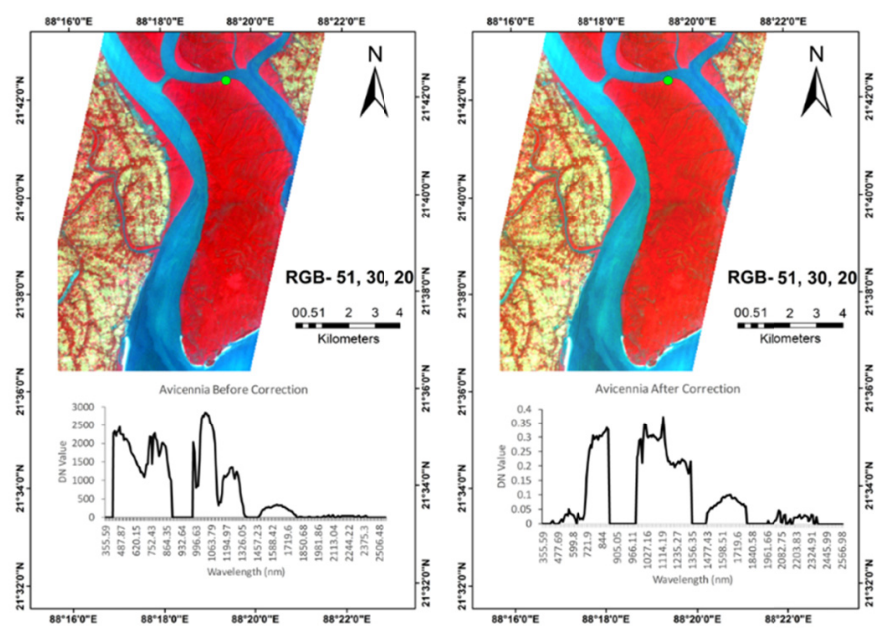

Figure 2. Comparison of pre- and post-correction images

Mangrove species-specific image spectra were then generated from corrected Hyperion imagery for a subset of GPS locations where field information on existing mangroves was collected (Figure 3). Absorption and peak reflectance detected from the spectral profile indicated the characteristics of each species. All remaining Hyperion images were classified with those detected spectral signatures using the Spectral Angle Mapper (SAM) in $\mathrm{ENVI}^{\mathrm{TM}}$.
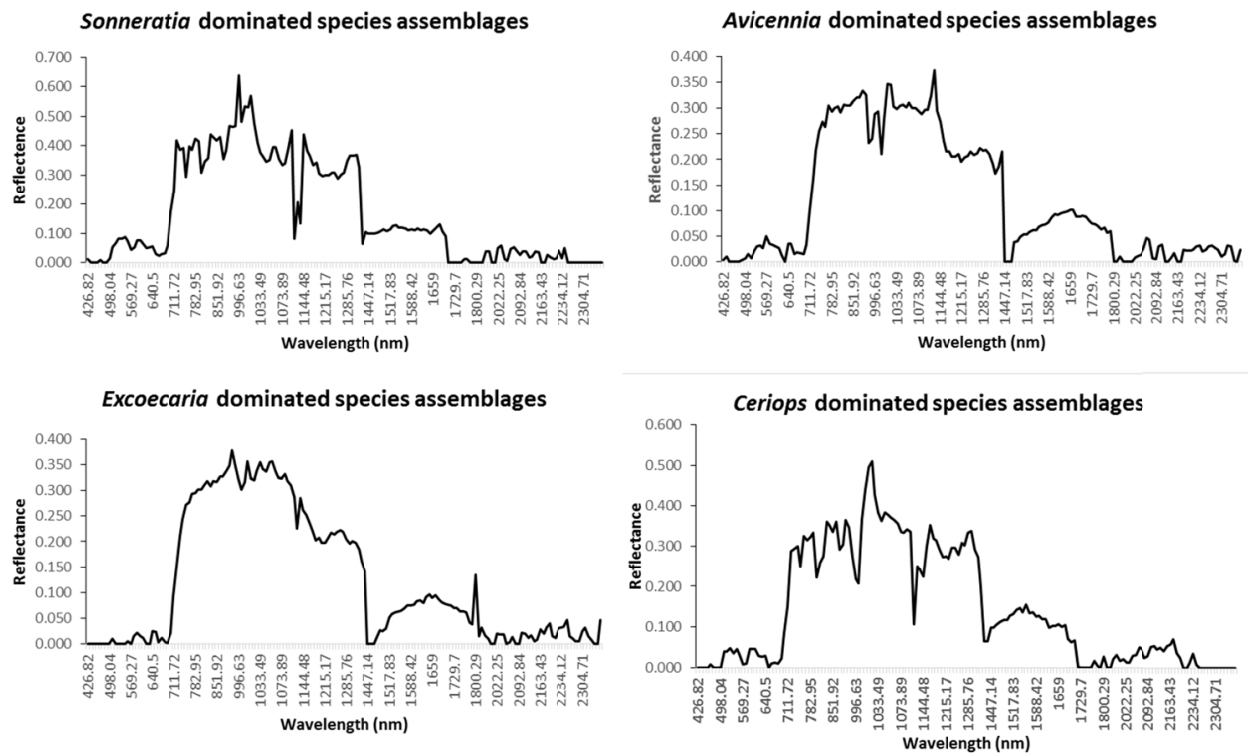

Figure 3. Spectra generated using the hyperspectral imagery and field survey samples 


\subsubsection{Image Rescaling and Classification Process}

Third, Landsat 8 OLI images were rescaled to Top of Atmosphere (TOA) radiance and TOA spectral reflectance, using the rescaling coefficient factor provided in the metadata (Appendix A). (Note 8) The corrected Landsat OLI images were then classified using an unsupervised process (with 200 classes), immediately followed by a knowledge-based classification process, whereby the knowledge engine built was based on the correlation between (i) the classified Hyperion images, (ii) the corrected OLI images, and (iii) the field information collected from 100 (of 141) ground-control points. Information from the other 41 ground-control points was later used to finalize the knowledge engine and accuracy assessment of the classified mangrove maps.

\subsubsection{Ground-Truthing the Images}

Finally, field data on the mangrove species and their assemblages were used to ground-truth the images. The classified images were shared with Sundarbans mangrove experts, and, based on their field experience, the images were revised. Subsequent re-testing of the mangrove species map showed that the level of accuracy had increased to 70 percent (Figure 4).

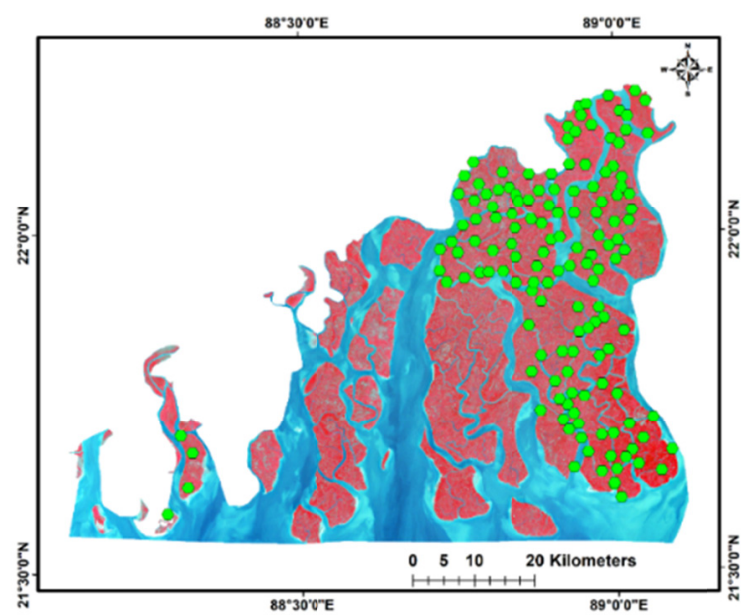

Figure 4. Map showing sampling points formangrove species identification in the Sundarbans

\subsection{Generate a Baseline Aquatic Salinity Profile for the Region}

Step 2 was to generate a baseline aquatic salinity profile for the Indian Sundarbans. A high-resolution spatial point file covering four years (2012-15) was created from the best available, location-specific monitored salinity data, using a multi-step process. (Note 9) Because salinity information for the Indian Sundarbans is quite limited, the analysis drew from the most comprehensive study to date on salinity impacts for the Bangladesh Sundarbans (an area of about $6,000 \mathrm{~km}^{2}$ ) in order to generate a broader picture of current and future salinity for the region (Dasgupta, Sobhan, \& Wheeler, 2018). (Note 10)

First, all spreadsheet monitoring information was converted into a spatial panel database. This was an unbalanced panel, with many time-series observations for some monitoring locations and sparse observations for others. A fixed-effects (FE) regression was then estimated, expressed as follows:

$$
\ln S_{i t}=\beta_{0}+\sum_{j=1}^{N} \beta_{j} D S_{j}+\sum_{k=2}^{12} \gamma_{k} D M_{k}+\delta y+\varepsilon_{i t},
$$

where $S$ equals salinity (ppt) at monitoring location $i$ for period $t, D S$ is the monitor dummy variable (1 for monitoring location $j$ and 0 otherwise), $D M$ equals the month dummy variable, and $y$ is the year $(2012,2013$, 2014, and 2015). The testing of various yearly trends in nine spatial clusters of monitors found no significant differences from the overall trend.

The next step was to generate a projection database for the four years (2012-15) with full dummy variables for monitoring locations and months. The projection database was used to predict salinity for all monitoring stations in all months and years. Predicted salinity was then extracted for all monitoring stations in the month of highest salinity (i.e., May 2015), and the observations were mapped in ArcGIS. Finally, a high-resolution point file was created via spatial interpolation among the observations. 


\subsection{Estimate Salinity Tolerance of Mangrove Types}

Step 3 computed the salinity tolerance ranges for the relevant mangrove species and mixed species. This was done using the geographic overlays of base mangrove distributions derived in Step 1, combined with the high-resolution, spatial aquatic salinity profile developed in Step 2.

\subsection{Project Future (2050) Location-specific Aquatic Salinity for the Region}

Step 4 estimated future aquatic salinity for the Indian Sundarbans. A projection model using high-resolution point data was first developed for the Bangladesh Sundarbans. For each point, the $S P$ ratio (salinity in 2012 divided by salinity in 2050) and the $S M$ ratio (salinity in 2012 divided by the maximum salinity in 2012 for all points) were computed. The $S P$ is distributed $(0,1)$. Fractional logit was then used to estimate $S P=\beta_{0}+\beta_{l} S M$ for all points. This functional form preserves the $(0,1)$ bound, while specifying the growth rate of salinity from 2012 to 2050 at a point as a function of the gap between its current salinity and the maximum salinity in the point set (i.e., effectively ocean salinity). The function fits the data extremely well.

To estimate salinity in 2050 for the Indian Sundarbans, the SM ratio (salinity in 2012 divided by the maximum salinity in 2012 for all points) was computed for each point. Next, the regression coefficients from the Bangladesh computation were used to estimate the $S P$ ratio (salinity in 2012 divided by salinity in 2050). Finally, $S P$ was used to compute salinity in 2050 and salinity in 2012 for each point.

\subsection{Project Future (2050) Spatial Distribution of Mangrove Species for the Region}

Step 5 estimated the impacts of progressive aquatic salinization by 2050 for mangrove species in the Indian Sundarbans. This was done using the 2015 basemap derived in Step 1, the salinity tolerance of various mangrove species computed in Step 3, and the location-specific aquatic salinity projected for 2050 in Step 4.

\section{Results}

The 2015 basemap generated from satellite images in this analysis shows that just 10 mangrove species and their assemblages predominate in the Indian Sundarbans. These are Avicennia alba, A. marina, and A. officinalis; Excoecaria agallocha; Ceriops decandra and C. Tagal; Bruguiera gymnorrhiza and B. cylindrical; Sonneratia apetala, S. alba, S. griffithii, and S. caseolaris; Heritiera fomes; Xylocarpus mekongensis and X. granatum; Rhizophora mucronata and R. opiculata; Phoenix paludosa; and Aegiceras corniculatum (Figure 5).

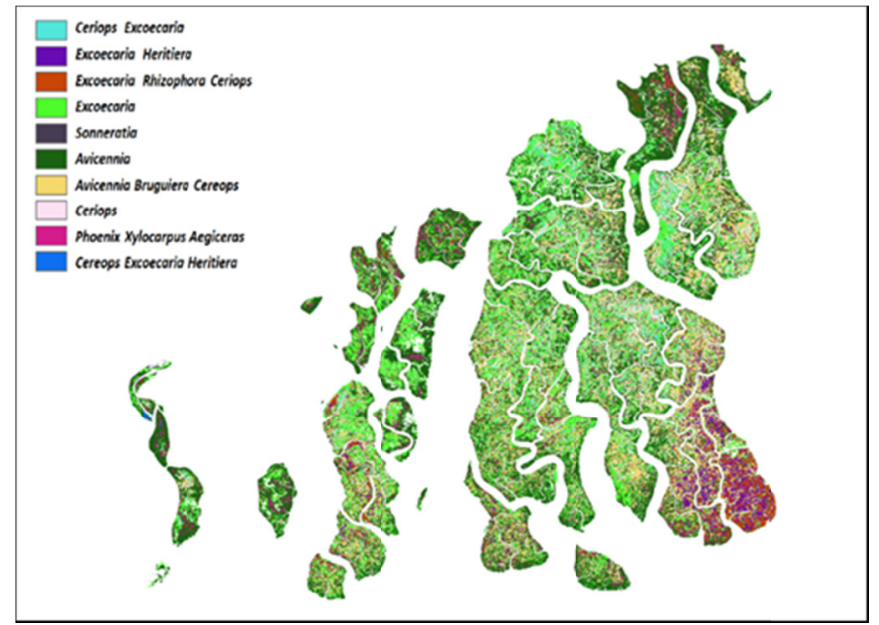

Figure 5. Basemap of mangrove distribution in the Indian Sundarbans, 2015

\subsection{Current and Future Aquatic Salinity Profiles for the Region}

The results show that current concentrations of maximum salinity in the Indian Sundarbans were already quite high in 2012 and that salinity will increase progressively by 2050 (Figure 6). 

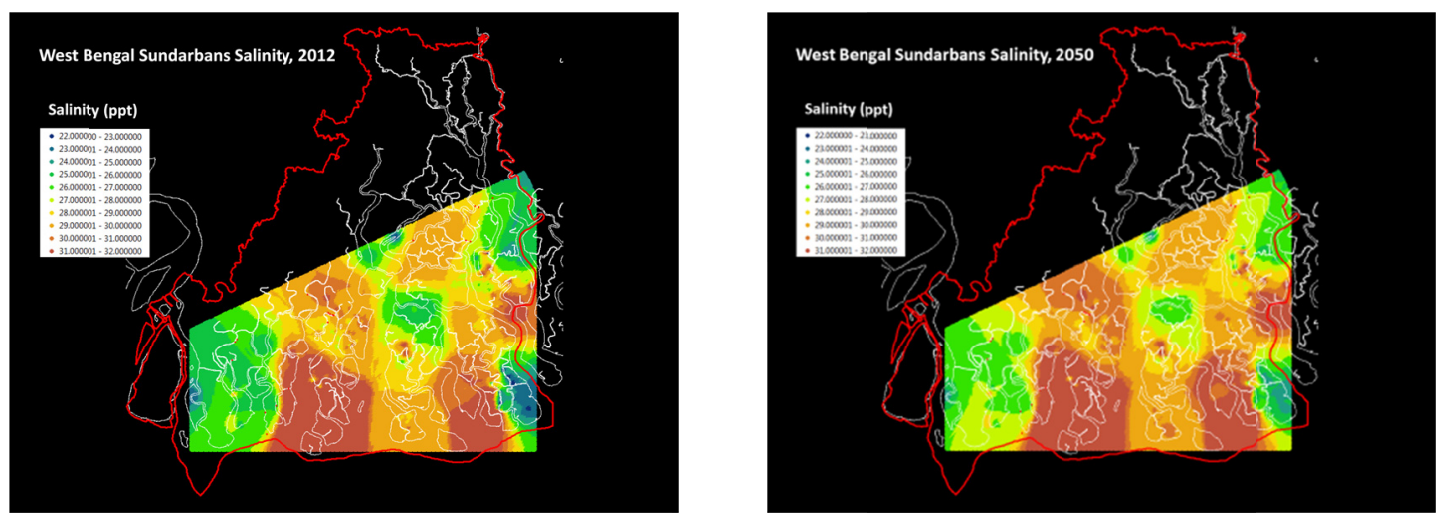

Figure 6. Maximum aquatic salinity ranges in the Indian Sundarbans, 2012 and 2050

By visually comparing the two maps in Figure 6, one can observe the scale of potential change between 2012 and 2050. Over time, salinity spreads northward and eastward with the ongoing rise in sea level, change in riverine flows, and subsidence in the lower Ganges Delta. As shown, the transition is quite pronounced in southwestern coastal, central, and northeastern areas.

\subsection{Salinity Tolerance of Mangrove Species and Assemblages}

From geographic overlays on the 2015 basemap and the corresponding aquatic salinity map, one can observe species clustering patterns by salinity range. These salinity-tolerance estimates are critical building blocks for analyzing the projected mangrove transition. The findings show clustering of Sonneratia and Heritiera species in areas with low-to-medium salinity; Phoenix, Excoecaria, Bruguiera, Xylocarpus, Aegiceras, and Rhizophora species in areas with medium-to-high salinity; and Avicennia and Ceriops species in high-salinity areas (Figure 7). (Note 11)

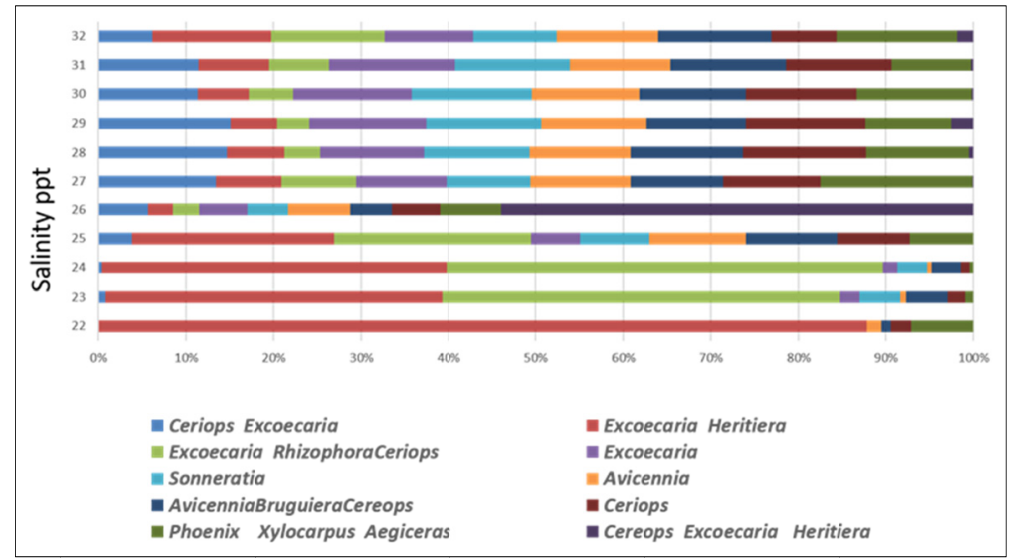

Figure 7. Clustering of mangrove species and assemblages within salinity ranges

\subsection{Projected Spatial Distribution of Mangrove Species in the Indian Sundarbans, 2050}

Figure 8 shows that, with progressive salinization, salt-tolerant mangroves will dominate the landscape of the Indian Sundarbans. These species and their assemblages include Avicennia, Excoecaria, Ceriops, Avicennia-Bruguiera-Ceriops, and Excoecaria-Rhizophora-Ceriops. This change will occur at the expense of freshwater species and assemblages with low-to-medium salt tolerance, including Sonneratia, Excoecaria-Heritiera, Excoecaria-Rhizophora-Ceriops, and Cereops-Excoecaria-Heritiera (Appendix B). 


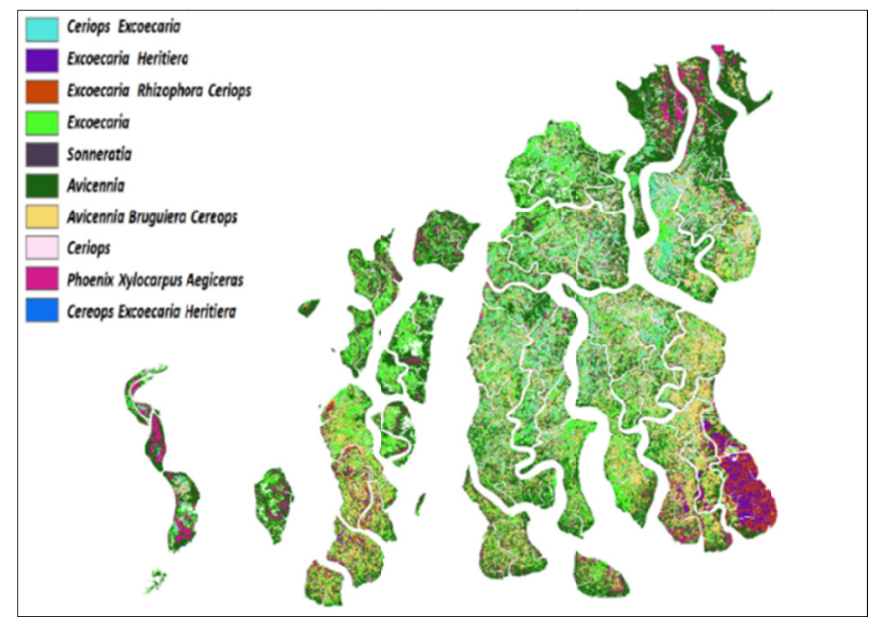

Figure 8. Map of mangrove distribution in the Indian Sundarbans, 2050

Figure 9 shows how progressive, climate-driven aquatic salinization is expected to impact mangrove migration by 2050. As shown, Phoenix xylocarpus-Aegiceras will see the largest net gain, followed by lesser gains for Ceriops-Excoecaria, Exoecaria, Avicennia, and Ceriops. Conversely, Excoecaria-Heritiera will suffer the largest net loss in area, with smaller losses for Excoecaria-Rhizophora-Ceriops, Avicennia-Bruguiera-Cereops, Sonneratia, and Ceriops-Excoecaria-Heritiera.

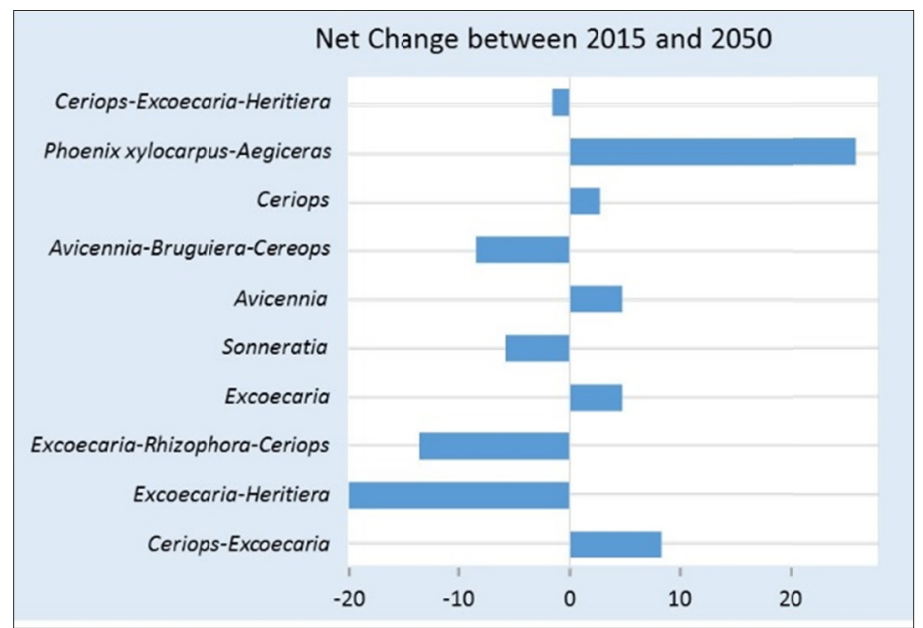

Figure 9. Absolute area gains and losses for mangrove species and assemblages, 2015-50

\section{Discussion and Recommendations}

The mangrove forests of the Indian Sundarbans provide a wide array of ecosystem services and household uses (Table 1). Most of the 4 million people who live in the coastal region depend on the mangrove forests for their livelihoods (e.g., fishing, honey collection, and tourism) and daily needs (e.g., water and fuelwood collection). 
Table 1. Ecosystem services and common uses of mangrove species in the Indian Sundarbans

\begin{tabular}{|c|c|c|c|c|c|c|c|c|c|c|}
\hline Mangrove species & $\begin{array}{l}\text { Timber } \\
\text { for } \\
\text { building } \\
\text { materials }\end{array}$ & $\begin{array}{l}\text { Fuel- } \\
\text { wood }\end{array}$ & Thatch & Medicine & $\begin{array}{l}\text { Food } \\
\text { (fruits, } \\
\text { leaves, } \\
\text { seeds) }\end{array}$ & $\begin{array}{l}\text { Fishing } \\
\text { equip- } \\
\text { ment }\end{array}$ & Tannin & $\begin{array}{l}\text { Honey } \\
\text { collection }\end{array}$ & $\begin{array}{l}\text { Environ- } \\
\text { mental } \\
\text { functions }^{\text {a }}\end{array}$ & $\begin{array}{l}\text { Fish } \\
\text { habitat }\end{array}$ \\
\hline Heritiera fomes & $\checkmark$ & $\checkmark$ & & $\checkmark$ & & & & o & o & o \\
\hline $\begin{array}{l}\text { Avicennia alba, A. } \\
\text { marina, A. } \\
\text { officinalis }\end{array}$ & $\checkmark$ & o & & $\checkmark$ & & o & & $\checkmark$ & $\checkmark$ & o \\
\hline $\begin{array}{l}\text { Sonneratia apetala, } \\
\text { S. alba, S. griffithii, } \\
\text { S. caseolaris }\end{array}$ & $\checkmark$ & o & & $\checkmark$ & $\checkmark$ & $\checkmark$ & & $\checkmark$ & o & o \\
\hline $\begin{array}{l}\text { Excoecaria } \\
\text { agallocha }\end{array}$ & $\checkmark$ & & & $\checkmark$ & & & & $\checkmark$ & $\checkmark$ & o \\
\hline $\begin{array}{l}\text { Ceriops decandra, } \\
\text { C. tagal }\end{array}$ & $\checkmark$ & $\checkmark$ & $\checkmark$ & $\checkmark$ & $\checkmark$ & o & $\checkmark$ & $\checkmark$ & o & o \\
\hline $\begin{array}{l}\text { Bruguiera } \\
\text { gymnonhiza, B. } \\
\text { cylindrical }\end{array}$ & $\checkmark$ & $\checkmark$ & & $\checkmark$ & $\checkmark$ & o & $\checkmark$ & & o & o \\
\hline $\begin{array}{l}\text { Rhizophora } \\
\text { mucronata, R. } \\
\text { apiculate }\end{array}$ & $\checkmark$ & $\checkmark$ & & $\checkmark$ & $\checkmark$ & $\checkmark$ & $\checkmark$ & & $\checkmark$ & $\checkmark$ \\
\hline $\begin{array}{l}\text { Xylocarpus } \\
\text { mekongensis, } \mathrm{X} . \\
\text { granatum }\end{array}$ & $\checkmark$ & o & & $\checkmark$ & & & $\checkmark$ & o & $\checkmark$ & o \\
\hline Phoenix paludosa & $\checkmark$ & $\checkmark$ & $\checkmark$ & & & & $\checkmark$ & & $\checkmark$ & o \\
\hline $\begin{array}{l}\text { Aegiceras } \\
\text { corniculatum }\end{array}$ & & $\checkmark$ & & $\checkmark$ & & & & $\checkmark$ & & o \\
\hline
\end{tabular}

Note. $(\checkmark)$ indicates information from the literature, and (o) is used to represent expert opinion.

a. Examples include trapping suspended sediment, preventing soil erosion, sequestering carbon, and mitigating the impact of natural disasters.

Traditionally, the intertidal zone where mangroves are found has been well-suited for breeding and rearing a variety of fish, crustacean, and mollusk species. (Note 12) But progressive aquatic salinization is expected to impact the food web, taking its toll on economically important fish catches with specific salinity-tolerance limits. Also, with changes in mangrove species combinations, honey collectors ("Moulis") may not fetch as high a price due to variations in the honey's fragrance and viscosity. In addition, reduced diversity of mangrove species could diminish tourism in the region. Furthermore, altered species combinations could increase salinity ingression, affecting the water table and thus water sources; women would shoulder a greater burden since they spend more hours collecting fuelwood and drinking water.

Engineering attempts to control rising salinity in the Indian Sundarbans are unlikely to succeed. Concerns over increasing aquatic salinity have not yet been incorporated into regional management protocols despite the Sundarbans' treaty-protected ecological status, which is widely acknowledged. Eastward meandering of the Ganges and Brahmaputra Rivers has already reduced freshwater inflows significantly. Even at the current sea level, strong tides may travel long distances upstream since the land is quite flat. Continuing sea-level rise will only exacerbate such tidal effects. As long as these dynamics continue, efforts to improve local ecological conditions through changes in hydrological regime (e.g., river training) will likely prove futile (Potkin, 2004).

The Indian Sundarbans is a UNESCO World Heritage site, and effective conservation management will require establishing baseline data for monitoring system changes over time, management protocols to maintain mangrove health, and support for mangrove regeneration and restoration. Location-specific baseline data is needed for tree-stand structures, tree abundance, species richness and diversity, export of nutrients, hydrological patterns, rates of sedimentation, and relative sea-level rise (McLeod \& Salm, 2006). Management protocols should include connectivity between mangrove systems and nearby river sources, as well as maintenance of upland freshwater catchments. Also, areas that are likely to survive climate-driven sea-level rise should be identified. In addition, monitoring of tidal fluctuations, varying $\mathrm{pH}$, and salinity is needed to support regeneration and colonization of suitable species, where necessary. Furthermore, restoration of currently degraded areas should be undertaken. (Note 13) 
Sea-level rise will continue beyond 2100, even if greenhouse gas emissions are stabilized in the near future. The impacts on globally-important mangrove ecosystems and the socioeconomic implications for vulnerable populations are substantial, suggesting that resources should also be directed to developing alternative livelihoods for mangrove-dependent households. It is hoped that this research will promote more widespread efforts to develop conservation and sustainable development policies that integrate rising salinity, changes in mangrove dynamics, and the welfare impacts on poor communities.

\section{Acknowledgments}

This research was funded by South Asia Water Initiative Trust Fund administered by the World Bank. The authors extend their special thanks to Kakoli Sengupta for her help with the data and to Anamitra Anurag Danda and Sunando Bandyopadhyay for their expert opinion. The authors are grateful to the Principal Chief Conservator of Forests, Wildlife \& Chief Wildlife Warden, West Bengal for providing forest entry permission along with all the necessary support to carry out the fieldwork in and around Sundarbans mangrove forest. They also thank Norma Adams for editing the article and Polly Means for help with the graphics.

\section{References}

Alongi, D. M. (2002). Present state and future of the world's mangrove forests. Environmental Conservation, 29(3), 331-349. https://doi.org/10.1017/S0376892902000231

Alongi, D. M. (2008). Mangrove forests: Resilience, protection from tsunamis and responses to global climate change. Estuarine, Coastal and Shelf Science, 76(1), 1-13. https://doi.org/10.1016/j.ecss.2007.08.024

Barik, J., Mukhopadhyay, A., Ghosh, T, Mukhopadhyay, S. K., Chowdhury, S. M., \& Hazra, S. (2018). Mangrove species distribution and water salinity: An indicator species approach to Sundarban. Journal of Coastal Conservation, 22(2), 361-368. https://doi.org/10.1039/c4em00611a

Barry, P. (2001). EO-1/Hyperion science data user's guide. Redondo Beach, CA: TRW Space, Defense \& Information Systems.

Bhadra, T., Mukhopadhyay, A., \& Hazra, D. (2017). Identification of river discontinuity using geo-informatics to improve freshwater flow and ecosystem services in Indian Sundarban Delta. In Environment and earth observation (pp. 137-152). Cham, Switzerland: Springer. https://doi.org/10.1007/978-3-319-46010-9_10

Blasco, F., Saenger, P., \& Janodet, E. (1996). Mangroves as indicators of coastal change. Catena, 27(3-4), 167178. https://doi.org/10.1016/0341-8162(96)00013-6

Brecht, H., Dasgupta, S., Laplante, B., Murray, S., \& Wheeler, D. (2012). Sea-level rise and storm surges: High stakes for a small number of developing countries. The Journal of Environment \& Development, 21(1), 120 138. https://doi.org/10.1177/1070496511433601

Cole, C. V., \& Vaidyaraman, P. P. (1966). Salinity distribution and effect of freshwater flows in the Hooghly River. In Proceedings of tenth conference on coastal engineering (pp. 1312-1434). Tokyo, Japan: ASCE. https://doi.org/10.9753/icce.v10.\%25p

Dasgupta, S., Laplante, B., Meisner, C., Wheeler, D., \& Yan, J. (2009). The impact of sea level rise on developing countries: A comparative analysis. Climatic Change, 93, 379-388. https://doi.org/10.1007/s10584-008-9499-5

Dasgupta, S., Huq, M., Khan, Z. H., Ahmed, M. M. Z., Mukherjee, N., Khan, M. F., \& Pandey, K. (2014). Vulnerability of Bangladesh to cyclones in a changing climate: Potential damages and adaptation cost. Climate and Development, 6, 96-110. https://doi.org/10.1080/17565529.2013.868335

Dasgupta, S., Kamal, F. A., Khan, Z. H., Choudhury, S., \& Nishat, A. (2015a). River salinity and climate change: Evidence from coastal Bangladesh. In J. Whalley \& J. Pan (Eds.), Asia and the world economy: Actions on climate change by Asian countries (pp. 205-242). World Scientific Press. https://doi.org/10.1142/9789814578622_0030

Dasgupta, S., Hossain, M. M., Huq, M., \& Wheeler, D. (2015b). Climate change and soil salinity: The case of coastal Bangladesh. Ambio, 44(8), 815-826. https://doi.org/10.1007/s13280-015-0681-5

Dasgupta, S., Sobhan, I., \& Wheeler, D. (2017). Impact of climate change and aquatic salinization on mangroves species in the Bangladesh Sundarbans. Ambio, 46(6), 680-694. https://doi.org/10.1007/s13280-017-0911-0

Dasgupta, S., Sobhan, I., \& Wheeler, D. (2018). Sea-level rise and species conservation in Bangladesh's Sundarbans region. Journal of Management and Sustainability, 8(1), 1. https://doi.org/10.5539/jms.v8n1p1 
Datt, B., McVicar, T. R., Van Niel, T. G., Jupp, D. L., \& Pearlman, J. S. (2003). Preprocessing EO-1 Hyperion hyperspectral data to support the application of agricultural indexes. IEEE Transactions on Geoscience and Remote Sensing, 41(6), 1246-1259. https://doi.org/10.1109/TGRS.2003.813206

Duggin, M. J., \& Robinove, C. J. (1990). Assumptions implicit in remote sensing data acquisition and analysis. Remote Sensing, 11(10), 1669-1694. https://doi.org/10.1080/01431169008955124

Ellison, J. C., \& Stoddart, D. R. (1991). Mangrove ecosystem collapse during predicted sea level rise: Holocene analogues and implications. Journal of Coastal Research, 7, 151-165. https://www.jstor.org/stable/4297812

Erwin, K. L. (2009). Wetlands and global climate change: The role of wetland restoration in a changing world. Wetlands Ecology and Management, 17, 71-84. https://doi.org/10.1007/s11273-008-9119-1

Farooq, S., \& Govil, H. (2014). Mapping regolith and gossan for mineral exploration in the eastern Kumaon Himalaya, India using Hyperion data and object oriented image classification. Advances in Space Research, 53(12), 1676-1685. https://doi.org/10.1016/j.asr.2013.04.002

Gilman, E., Van Lavieren, H., Ellison, J. C., Jungblut, V., Wilson, L., Areki, F., Brighouse, G., ... Bungitak, J. (2006). Pacific island mangroves in a changing climate and rising sea. Regional Seas Report and Studies No. 179. Nairobi, Kenya: United Nations Development Programme.

Gopal, B., \& Chauhan, M. (2006). Biodiversity and Its conservation in the Sundarban mangrove ecosystem. Aquatic Sciences, 68(3), 338-354. https://doi.org/10.1007/s00027-006-0868-8

Hansen, J., Sato, M., Kharecha, P., \& Schuckmann, K. V. (2011). Earth's energy imbalance and implications. Atmospheric Chemistry and Physics, 11(24), 13421-13449. https://doi.org/10.5194/acp-11-13421-2011

Institute of Water Modeling. (2003). Sundarban biodiversity conservation project: Surface water modeling. Final Report. Dhaka, Bangladesh: Institute of Water Modeling, Ministry of Environment and Forests, Government of Bangladesh.

Islam, S. N., \& Gnauck, A. (2008). Mangrove wetland and ecosystems in Ganges-Brahmaputra Delta in Bangladesh. Frontiers of Earth Science in China, 2(4), 439-448. https://doi.org/10.1007/s11707-008-0049-2

Lange, G. M., Dasgupta, S., Thomas, T., Murray, S., Blankespoor, B., Sander, K., \& Essam, T. (2010). Economics of adaptation to climate change-ecosystem services. World Bank Discussion Paper No. 7. Washington, DC: World Bank.

McLeod, E., \& Salm, R. V. (2006). Managing mangroves for resilience to climate change. Gland, Switzerland: The World Conservation Union (IUCN).

Nandy, S., \& Kuswaha, S. P. S. (2011). Study on the utility of IRS 1D LISS-III data and the classification techniques for mapping of Sundarban mangroves. Journal of Coastal Conservation, 15(1), 123-137. https://doi.org/10.1007/s11852-010-0126-z

Naskar, K. R. (1988). Economic potentialities of the tidal mangrove forests of Sundarbans in India. Journal of Indian Society of Coastal Agricultural Research, 6(2), 149-157.

Petersen, L., \& Shireen, S. (2001). Soil and water salinity in the coastal area of Bangladesh. Dhaka, Bangladesh: Bangladesh Soil Resources Development Institute.

Pfeffer, W. T., Harper, J. T., \& O'Neel, S. (2008). Kinematic constraints on glacier contributions to $21^{\text {st }}$-century sea-level rise. Science, 321, 1340-1343. https://doi.org/10.1126/science.1159099.

Potkin, A. (2004). Watering the Bangladesh Sundarbans. In M. M. Q. Mirza (Ed.), The Ganges water dispersion: Environmental effects and implications (pp. 163-176). Dordrecht, the Netherlands: Kluwer Academic Publishers. https://doi.org/10.1007/978-1-4020-2792-5

Rahmstorf, S. (2007). A semi-empirical approach to projecting future sea-level rise. Science, 315, 368-370. https://doi.org/10.1126/science.1135456

Rao, A. N. (1987). Mangrove ecosystems of Asia and the Pacific. In Technical report of the UNDP/UNESCO research and training pilot programme on mangrove ecosystems in Asia and the Pacific (RAS/79/002) (pp. 1-48). Quezon City, Philippines: JMC Press.

Semeniuk, V. (1994). Predicting the effect of sea level rise on mangroves in northwestern Australia. Journal of Coastal Research, 10, 1050-1076. Retrieved from http://www.jstor.org/stable/4298296

Soil Resources Development Institute. (2000). Soil salinity in Bangladesh 2000. Dhaka, Bangladesh: Soil Resources Development Institute. 
Soil Resources Development Institute. (2010). Soil salinity in Bangladesh 2010. Dhaka, Bangladesh: Soil Resources Development Institute.

United Kingdom Department of Environment, Food and Rural Affairs. (2007). Investigating the impact of relative sea-level rise on coastal communities and their livelihoods in Bangladesh. Dhaka, Bangladesh: Institute of Water Modeling and Center for Environment and Geographic Information Services.

United Nations Environment Programme. (1994). Assessment and monitoring of climate change impacts on mangrove ecosystems. UNEP Regional Seas Reports and Studies No. 154. Nairobi, Kenya: United Nations Environment Programme.

Vermeer, M., \& Rahmstorf, S. (2009). Global sea level linked to global temperature. Proceedings of the National Academy of Sciences, 106, 21527-21532. https://doi.org/10.1073/pnas.0907765106

\section{Notes}

Note 1. Current scientific estimates are that sea level may rise by $1 \mathrm{~m}$ or more in this century, globally affecting some 1 billion people by 2050 (Hansen et al., 2011; Vermeer \& Rahmstorf, 2009; Pfeffer, Harper, \& O’Neel, 2008; Rahmstorf, 2007; Dasgupta et al., 2009; Brecht et al., 2012); a rise of $3 \mathrm{~m}$ or more by 2100 is feared in light of new evidence on ice-cliff instability of the Antarctic. https://www.nature.com/articles/nature17145; http://www.nature.com/news/antarctic-model-raises-prospect-of-unstoppable-ice-collapse-1.19638;

https:/climatefeedback.org/evaluation/antarctica- doomsday-glaciers-could-flood-coastal-cities-grist-eric-holthaus/

Note 2. Rao (1987) reported that the Indian mangroves consisted of 60 species, while Naskar (1988) reported 35 true mangroves and Blasco, Saenger, \& Janodet (1996) reported 58 species.

Note 3. Freshwater flow has become increasingly restricted since the 1975 construction of the Farakka Barrage Township; between 1962 and 2006, water discharge of the Ganges fell from 3,700 $\mathrm{m}^{3}$ per second to $364 \mathrm{~m}^{3}$ per second, strangling an already parched ecosystem and thus making the distributary networks more dependent on tidal flow bringing in sea water from the Bay of Bengal (Islam and Gnauck, 2008).

Note 4. The groundwater is also saline, except for a few meter-thick, confined aquifers.

Note 5. The acquisition date of the Landsat 8 OLI data is March 18, 2015 and the path/row is $138 / 45$. Landsat 8 OLI has 9 spectral channels, ranging from visible to shortwave infrared bands. The spatial resolution is comparable to the ETM+. Temporal resolution of Landsat 8 is 16 days. Hyperspectral data from Hyperion were processed and used for the spectral signature generation of various mangrove species. The acquisition dates of the Hyperion data are September 10, 2011, November 23, 2014, and November 13, 2016 and the path/row is 138/45. Hyperion images have 242 bands that include both Visible and Near Infrared (VNIR) and Shortwave Infrared (SWIR), having a spectral range of 357 to $2,576 \mathrm{~nm}$ with a spectral interval of $10 \mathrm{~nm}$.

Note 6. Bad bands were removed while converting Digital Number (DN) value to radiance using the radiometric calibration tool. The output was converted to band-interleaved-by line (BIL) radiance image with floating point values as Fast Line-of-sight Atmospheric Analysis of Spectral Hypercube (FLAASH) correction module use BIL format.

Note 7. During the acquisition of Hyperion data, vertical striping occurs at times due to poor calibration of push broom sensors. For this analysis, de-striping was performed by filling up the DN value of the gap line with an average DN value from the previous and the next column (Farooq \& Govil, 2014). Atmospheric correction was performed using the FLAASH package available in ENVI ${ }^{\mathrm{TM}}$.

Note 8. Gain and bias corrections of satellite data through radiometric calibration are prerequisites for the classification and detection of change from the multi-temporal images (Duggin \& Robinove, 1990).

Note 9. At present, there is no geo-coded database on aquatic or soil salinity for the Indian Sundarbans. Data was compiled from field measurements taken by the Nature Environment \& Wildlife Society (NEWS) and World Wildlife Fund-India (WWF-India).

Note 10. This study draws extensively on spatial data from the Aquatic Salinity Information System (RSIS) for southwest coastal Bangladesh, including the Sundarbans. The RSIS provides location-specific salinity estimates for December 2011, January-June 2012, December 2049, and January-June 2050 under 27 climate-change scenarios.

http://sdwebx.worldbank.org/climateportal/index-cfm?page=websalinity_dynamics\&ThisRegion=Asia\&ThisCco $\mathrm{de}=\mathrm{BGD}$ 
Note 11. These findings are in line with those of Barik et al., 2018.

Note 12. The direct relationships between particular mangrove and fish species are still being investigated.

Note 13. Community-based mangrove restoration activities could engage local women's groups in nursery preparation of salt-tolerant species.

\section{Appendix A}

\section{Processing of Landsat 8 OLI}

Gain and bias corrections of satellite data through radiometric calibration are prerequisites for the classification and detection of change from multi-temporal images (Duggin \& Robinove, 1990). Therefore, Landsat 8 data products were first rescaled to Top of Atmosphere (TOA) radiance and TOA spectral reflectance, using the rescaling coefficient factor provided in the metadata.

The OLI data were converted to TOA radiance, using the following conversion equation:

$$
L_{\lambda}=M_{L} \times Q_{c a l}+A_{L},
$$

where $L_{\lambda}$ equals TOA radiance (Watts $\left./ \mathrm{m}^{2} \mathrm{x} \operatorname{srad} \mathrm{x} \mu \mathrm{m}\right), M_{L}$ is the band-specific multiplicative rescaling, $Q_{c a l}$ is the quantized and calibrated standard product pixel values (DN), and $A_{L}$ is equivalent to the band-specific additive rescaling factor.

The OLI data were converted to TOA reflectance, using the following conversion equation:

$$
\rho_{\lambda}^{\prime}=M_{\rho} \times Q_{c a l}+A_{\rho}
$$

where $\rho_{\lambda}^{\prime}$ equals TOA planetary reflectance without correction for solar angle, $M_{\rho}$ equals the band-specific multiplicative rescaling factor, $Q_{c a l}$ is the quantized and calibrated standard product pixel values $(\mathrm{DN})$, and $A_{\rho}$ equals the band-specific additive rescaling factor.

TOA reflectance was then corrected with the solar zenith angle, expressed as follows:

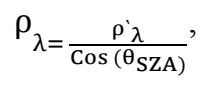

where $\rho_{\lambda}$ equals TOA reflectance and $\theta_{S Z A}$ is the solar zenith angle. 


\section{Appendix B}

Estimated Change in Area $\left(\mathrm{km}^{2}\right)$ for Various Mangrove Species and Assemblages, 2015-2050

\begin{tabular}{|c|c|c|c|c|c|c|c|c|c|c|}
\hline \multirow{2}{*}{$\begin{array}{l}\text { Mangrove } \\
\text { species and } \\
\text { assemblages, } \\
2015\end{array}$} & \multicolumn{10}{|c|}{ Mangrove species and assemblages, 2050} \\
\hline & $\begin{array}{l}\text { Ceriops- } \\
\text { Excoecaria }\end{array}$ & $\begin{array}{l}\text { Excoecaria- } \\
\text { Heritiera }\end{array}$ & $\begin{array}{l}\text { Excoecaria- } \\
\text { Rhizophora- } \\
\text { Ceriops }\end{array}$ & Excoecaria & Sonneratia & Avicennia & $\begin{array}{l}\text { Avicennia- } \\
\text { Bruguiera- } \\
\text { Cereops }\end{array}$ & Ceriops & $\begin{array}{l}\text { Phoenix- } \\
\text { Xylocarpus- } \\
\text { Aegiceras }\end{array}$ & $\begin{array}{l}\text { Ceriops- } \\
\text { Excoecaria- } \\
\text { Heritiera }\end{array}$ \\
\hline $\begin{array}{l}\text { Ceriops- } \\
\text { Excoecaria }\end{array}$ & 65.967 & 0.727 & 0.819 & 16.842 & 0.212 & 1.130 & 4.211 & 0.0054 & 0.005 & 0 \\
\hline $\begin{array}{l}\text { Excoecaria- } \\
\text { Heritiera }\end{array}$ & 0.624 & 32.206 & 2.133 & 4.685 & 0.252 & 12.408 & 14.955 & 0.514 & 0.418 & 0 \\
\hline $\begin{array}{l}\text { Excoecaria- } \\
\text { Rhizophora- } \\
\text { Ceriops }\end{array}$ & 0.092 & 0.063 & 299.115 & 2.525 & 0.121 & 11.126 & 4.910 & 0.358 & 2.291 & 0 \\
\hline Excoecaria & 16.262 & 4.046 & 25.29 & 353.500 & 0.061 & 6.203 & 8.616 & 0.018 & 0.934 & 0 \\
\hline Sonneratia & 0.243 & 0.684 & 4.5 & 0 & 35.007 & 2.885 & 1.356 & 0 & 0.671 & 0 \\
\hline Avicennia & 4.095 & 0.838 & 12.978 & 14.871 & 0 & 718.681 & 0.005 & 4.986 & 0.049 & 0.084 \\
\hline $\begin{array}{l}\text { Avicennia- } \\
\text { Bruguiera- } \\
\text { Cereops }\end{array}$ & 8.619 & 7.026 & 29.907 & 0 & 0 & 23.820 & 338.535 & 5.543 & 2.638 & 0 \\
\hline Ceriops & 1.715 & 0.939 & 5.814 & 4.23 & 0.027 & 4.478 & 12.323 & 148.762 & 1.871 & 0 \\
\hline $\begin{array}{l}\text { Phoenix- } \\
\text { Xylocarpus- } \\
\text { Aegiceras }\end{array}$ & 0.017 & 0.023 & 1.8 & 0.579 & 0.123 & 6.485 & 1.256 & 2.828 & 47.110 & 0 \\
\hline $\begin{array}{l}\text { Ceriops- } \\
\text { Excoecaria- } \\
\text { Heritiera }\end{array}$ & 0 & 0 & 0.198 & 0.003 & 0 & 0.824 & 0 & 0.001 & 0.379 & 0.001 \\
\hline
\end{tabular}

\section{Copyrights}

Copyright for this article is retained by the authors, with first publication rights granted to the journal.

This is an open-access article distributed under the terms and conditions of the Creative Commons Attribution license (http://creativecommons.org/licenses/by/4.0). 